\section{Microporous sulfur-doped carbon from thienyl-based polymer network precursors $\dagger$}

\author{
Jens Peter Paraknowitsch, Arne Thomas and Johannes Schmidt* \\ Received 19th April 2011, Accepted 27th May 2011 \\ DOI: $10.1039 / \mathrm{c} 1 \mathrm{cc12272j}$
}

Porous sulfur-doped carbon was synthesised by using a thienylbased polymer network as a precursor. The sulfur amount varies from 5-23 $\mathrm{m} \%$ while the materials show microporosity with BET surface areas of up to $711 \mathrm{~m}^{2} \mathrm{~g}^{-1}$.

Heteroatom doping of carbon materials is a major tool for tuning their properties, especially with nitrogen as a dopant. ${ }^{1-15}$ The doped materials have altered properties, giving rise to various applications, e.g. as electrodes in supercapacitors $8,10,12,13,16,17$ or as electrocatalysts for the oxygen reduction reaction (ORR) in fuel cells. ${ }^{9,11,18-23}$ Besides nitrogen, boron is another dopant of current interest, e.g. in carbon nanotube or graphene research. ${ }^{24-26}$ More recently materials scientists have started to focus on sulfur doping. This is yielding interesting and beneficial influences on the properties of the envisaged carbon materials: graphite-sulfur-composites that exhibit superconductive properties have already been presented. ${ }^{27,28}$ Going from composites to sulfur-doped carbons, the band structures of the materials are modified and can be tuned depending on the amount of sulfur atoms, e.g. in sulfur-doped graphene. ${ }^{29,30}$ These sulfur-doped graphenes can be synthesised by adsorption of thiol groups at defect sites, ${ }^{29,31}$ and they are discussed as potential sensors for polluting gases, such as $\mathrm{NO}_{x} \cdot{ }^{32}$ Furthermore, S-doped carbon nanotubes with altered electronic properties, ${ }^{33}$ or even S-doped graphitic carbon nitride materials for photocatalysis $^{34}$ are discussed. These versatile works represent the growing interest in sulfur-doped carbon materials. Our interest was to synthesise sulfur-doped carbon based on sulfur rich precursors via thermal treatment in a one-step process. This concept of thermolysis of heteroatom rich precursors for the synthesis of doped carbonaceous materials has been applied frequently, e.g. by using ionic liquids with dicyanamide anions and nitrogen-rich cations in the synthesis of $\mathrm{N}$-doped carbon. ${ }^{1-4}$ Furthermore microporous covalent triazine networks have been shown to form porous nitrogen-rich carbon materials with a remarkably high active surface area upon annealing. ${ }^{35,36}$ Transferring this concept to sulfur-doping, a microporous

Technical University of Berlin, Institute of Chemistry,

Functional Materials, Englische Straße 20, 10587 Berlin, Germany.

E-mail: johannes.schmidt@tu-berlin.de; Fax: + 49(0)30 31429271;

Tel: + 49 (0)30 31425241

$\dagger$ Electronic supplementary information (ESI) available: Experimental details and additional figures. See DOI: $10.1039 / \mathrm{clcc} 12272 \mathrm{j}$ poly(1,3,5-tris(thienyl)benzene) (PTTB) network ${ }^{37}$ has been selected as a precursor (compare Fig. 1). Besides its high amount of sulfur atoms due to the thienyl units, the microporosity represents a further advantage as it is most likely to induce intrinsic porosity in the carbonaceous materials. It is most interesting to see that the crosslinked structure of the precursor network is the crucial key to the formation of the S-doped carbon material: comparing the thermogravimetric results for the PTTB-network and its monomer (Fig. 2), the monomeric structure appears to evaporate completely upon thermal treatment in an inert gas atmosphere (boiling point: $\left.310{ }^{\circ} \mathrm{C}\right),{ }^{38}$ while the crosslinked microporous network yields high residual masses of $\sim 68 \%$ at a temperature as high as $900{ }^{\circ} \mathrm{C}$.

We thermally treated the thienyl-based network in an argon atmosphere at temperatures of $600{ }^{\circ} \mathrm{C}, 700{ }^{\circ} \mathrm{C}, 800{ }^{\circ} \mathrm{C}, 900{ }^{\circ} \mathrm{C}$

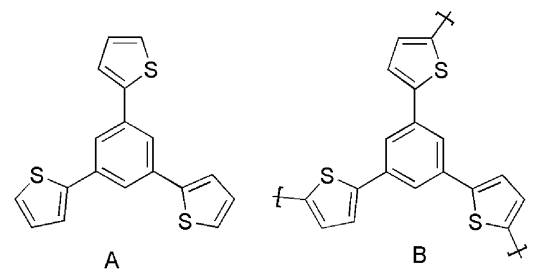

Fig. 1 (A) 1,3,5-tris(thienyl)benzene and (B) poly(1,3,5-tris(thienyl)benzene).

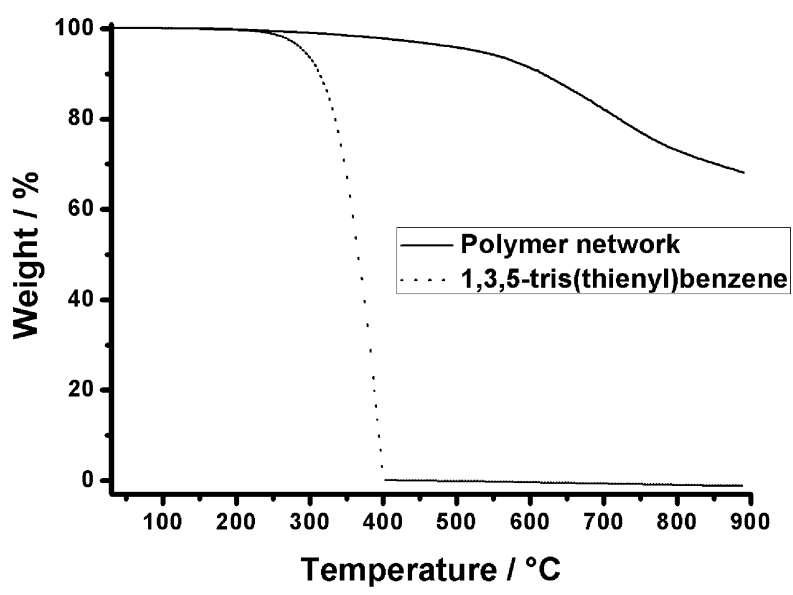

Fig. 2 Thermogravimetric analysis for a polymer network precursor and the respective monomer, measured under inert gas. 
Table 1 Sulfur contents of doped carbon materials synthesised at different temperatures

\begin{tabular}{llllll}
\hline & $600{ }^{\circ} \mathrm{C}$ & $700{ }^{\circ} \mathrm{C}$ & $800{ }^{\circ} \mathrm{C}$ & $900{ }^{\circ} \mathrm{C}$ & $1000{ }^{\circ} \mathrm{C}$ \\
\hline $\mathrm{S} / \mathrm{m} \%$ & 23.2 & 18.0 & 13.5 & 9.3 & 5.6 \\
\hline
\end{tabular}

and $1000{ }^{\circ} \mathrm{C}$. The synthesis procedures yield homogeneously black solids with varying sulfur contents according to combustion analysis results (see Table 1). The crosslinked structure of the precursor inhibits a complete decomposition, while the elimination of sulfur atoms is partially suppressed due to the lack of available protons neighbouring the sulfur atoms, as the thienyl units are known to decompose via the elimination of $\mathrm{H}_{2} \mathrm{~S} .{ }^{39}$ Thus the sulfur content of the targeted materials can be facilely tuned by simply adjusting the reaction temperature.

It can be expected that the chemical environment of the sulfur and its incorporation into the carbon forming network is altered the more the reaction temperature is increased. This can be further followed by FT-IR spectroscopy (see Fig. S1, ESI $\dagger$ ): upon increasing the temperature of synthesis, carbonisation is proceeding, yielding a lack of IR-active functional groups, while the sulfur atoms are directly incorporated into the forming carbon backbone. For gaining more insight into this molecular structure, X-ray photoelectron spectroscopy (XPS) has been performed on samples synthesised at $1000{ }^{\circ} \mathrm{C}$. Detailed scans for the $\mathrm{C} 1 \mathrm{~s}$ and the $\mathrm{S} 2 \mathrm{p}$ orbitals including their deconvolutions are shown in Fig. S2 (ESI $\dagger)$ and Fig. 3. The $\mathrm{C} 1 \mathrm{~s}$-scan reveals a dominant contribution of graphite-like carbon in an aromatic environment $(284.5 \mathrm{eV}) .{ }^{40-43}$ Further there are minor contributions to the XPS signal at binding energies of $286.0 \mathrm{eV}$ and $288.8 \mathrm{eV}$, respectively. Those very broadened contributions can be assigned to sulfur-bound carbon atoms, ${ }^{44,45}$ but oxidative contaminations cannot be excluded, either. ${ }^{43,46,47}$ The according spectrum of the S-2p orbital (see Fig. 3) exhibits a higher complexity, among other things due to spin-orbit coupling phenomena. A clear assignation is difficult, especially being based on these data obtained by deconvolution. Nevertheless the values coincide with data from the literature. There are minor contributions (165.6 eV, $166.7 \mathrm{eV}$, and $168.8 \mathrm{eV}$ ) of oxidised sulfur species, such as sulfonate and sulfate groups. Values of $168.7 \mathrm{eV}$ are e.g. known to refer to sulfur atoms in sulfonated aromatic systems, which fits the carbon material under discussion. ${ }^{48}$ Nevertheless, sulfur is dominantly found in other valence states, as the spectrum reveals more pronounced contributions

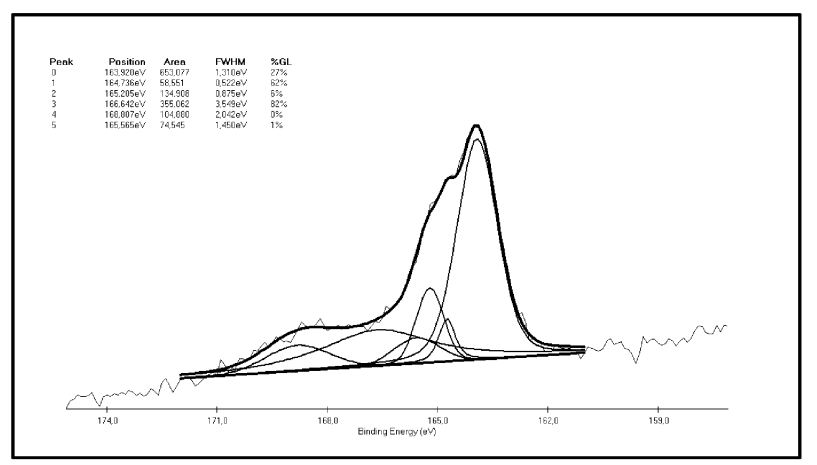

Fig. 3 Deconvoluted XPS spectrum of the S-2p-orbital, measured on the sample synthesis at $1000{ }^{\circ} \mathrm{C}$. at binding energy values of $163.9 \mathrm{eV}, 164.7 \mathrm{eV}$ and $165.2 \mathrm{eV}$. They all refer to carbon-bound sulfur atoms: $163.8 \mathrm{eV}$ is a binding energy known from $\mathrm{S}-\mathrm{S}$ bonds between two aromatic rings, $163.9 \mathrm{eV}$ can be assigned to other $\mathrm{S}-\mathrm{S}$ bonds neighbouring carbon atoms, and to $\mathrm{C}=\mathrm{S}$ double bonds. Sulfur atoms in monomeric thiophenes exhibit energy values for the $2 p$ orbital of $164.5 \mathrm{eV}$, a structural motif that is most likely to be found in our materials, according to the molecular structure of the precursor. ${ }^{48}$ Nevertheless this is not the most prominent peak in the spectrum, which shows that structural rearrangements are taking place upon carbonisation of the network towards other $\mathrm{C} / \mathrm{S}$ binding motifs. It can thus be concluded a predominance of sulfur atoms that are directly incorporated into the carbon backbone of the material. This is not only in agreement with the XPS spectrum exhibiting only little contributions that can be assigned to oxidised sulfur species. Furthermore, the structure of the precursor is most unlikely to induce the mere formation of surface functionalities.

Quantitative evaluations of the XPS measurements revealed an atomic sulfur content of $2.6 \mathrm{~mol} \%$ which refers to $\sim 7 \mathrm{~m} \%$ of sulfur bound in the material. This value is in agreement with the data obtained from elemental combustion analysis and only slightly exceeds these values (compare Table 1).

Nitrogen sorption isotherms that have been measured for all sulfur-doped carbonaceous materials synthesised throughout this work reveal their microporosity and high active surface areas. Fig. 4 represents the respective isotherm for the material synthesised at $1000{ }^{\circ} \mathrm{C}$, in direct comparison to the precursor network. From the shape of the isotherm and its pronounced slope at very low values of relative pressure, it is obvious that the microporous morphology of the precursor network is maintained in the sulfur-doped carbon. The uptake of nitrogen at relative pressures close to unity indicates also external surface area which results from interspaces between agglomerated particles (see SEM micrographs in Fig. S3/S4, ESI $\dagger$ ). Identical observations can be made for all other synthesis temperatures that have been applied, as it can be observed in Fig. S5-S8 $(\mathrm{ESI} \dagger)$. BET evaluations reveal active surface areas that are slightly reduced with respect to the precursor polymer network (see Table 2).

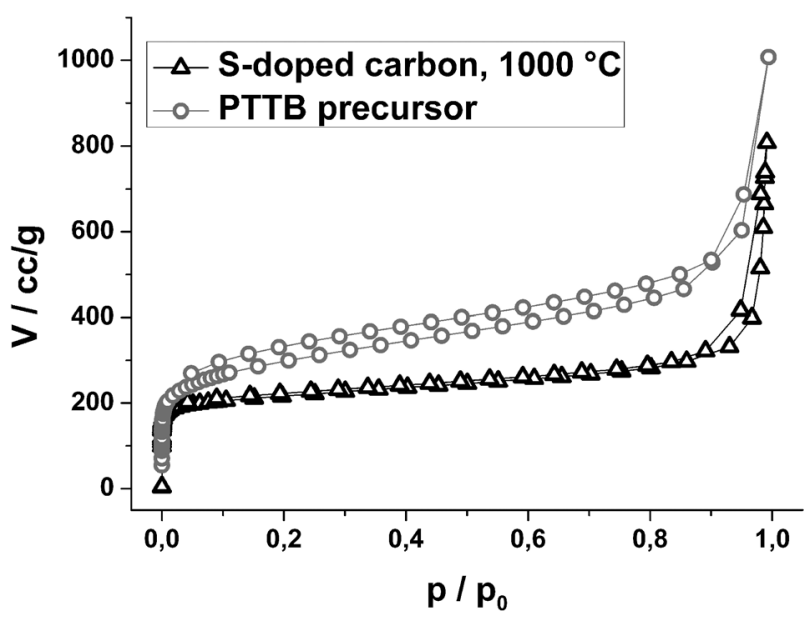

Fig. 4 Nitrogen sorption isotherms of precursors polymer network and carbonised sulfur doped material. 
Table 2 Active surface areas (BET) and pore volumes of S-doped carbonaceous materials synthesised at different temperatures

\begin{tabular}{|c|c|c|c|c|c|c|}
\hline & Precursor $^{37}$ & $600^{\circ} \mathrm{C}$ & $700^{\circ} \mathrm{C}$ & $800^{\circ} \mathrm{C}$ & $900^{\circ} \mathrm{C}$ & $1000{ }^{\circ} \mathrm{C}$ \\
\hline $\mathrm{SA} / \mathrm{m}^{2} \mathrm{~g}^{-1}$ & 1060 & 599 & 614 & 615 & 668 & 711 \\
\hline$V_{\text {micropore }} / \mathrm{cm}^{3} \mathrm{~g}^{-1}$ & 0.26 & 0.20 & 0.13 & 0.17 & 0.22 & 0.24 \\
\hline
\end{tabular}

Interestingly, the surface area drops from $1060 \mathrm{~m}^{2} \mathrm{~g}^{-1}$ to $599 \mathrm{~m}^{2} \mathrm{~g}^{-1}$ when the precursor is thermally treated at $600{ }^{\circ} \mathrm{C}$. When increasing the temperature of synthesis stepwise to $1000{ }^{\circ} \mathrm{C}$ the surface area is growing again. Similar effects are observed for the micropore volume at higher reaction temperatures, reaching a value of $0.24 \mathrm{~cm}^{3} \mathrm{~g}^{-1}$ at $1000{ }^{\circ} \mathrm{C}$ (compare Table 2). It seems that first the porous structure of the precursor is at least partially collapsing throughout the thermal treatment process. Nevertheless due to the crosslinked structure the preconditions for microporosity are maintained so that upon further elimination of side products, such as carbon and sulfur residues, additional pores are created and the surface area increases again.

In summary, we used a thienyl-based microporous polymer network as a precursor for the synthesis of sulfur doped carbon. The precursor provides a high content of sulfur that is maintained upon thermal treatment in an inert gas atmosphere. Varying the synthesis temperature enables the tuning of the sulfur content between $5 \mathrm{~m} \%$ and $23 \mathrm{~m} \%$. As the microporosity of the precursor is also kept, the material has to be considered as a promising support material for the immobilisation of metal nanoparticles which is a subject of current studies.

Financial support from the Cluster of Excellence "Unifying Concepts in Catalysis" (supported by the Deutsche Forschungsgemeinschaft and administered by the TU Berlin) and the DFG project "Nanocarbon" (10033287) is gratefully acknowledged. We thank Dr Anna Fischer for SEM measurements and Dr Yuanjian Zhang (NIMS) for XPS measurements.

\section{Notes and references}

1 J. S. Lee, X. Q. Wang, H. M. Luo, G. A. Baker and S. Dai, J. Am. Chem. Soc., 2009, 131, 4596-4597.

2 J. S. Lee, X. Q. Wang, H. M. Luo and S. Dai, Adv. Mater., 2010, 22, 1004-1007.

3 J. P. Paraknowitsch, A. Thomas and M. Antonietti, J. Mater. Chem., 2010, 20, 6746-6758.

4 J. P. Paraknowitsch, J. Zhang, D. S. Su, A. Thomas and M. Antonietti, Adv. Mater., 2010, 22, 87-92.

5 L. Zhao, N. Baccile, S. Gross, Y. J. Zhang, W. Wei, Y. H. Sun, M. Antonietti and M. M. Titirici, Carbon, 2010, 48, 3778-3787.

6 L. Zhao, Z. Bacsik, N. Hedin, W. Wei, Y. H. Sun, M. Antonietti and M. M. Titirici, ChemSusChem, 2010, 3, 840-845.

7 L. Zhao, R. Crombez, F. P. Caballero, M. Antonietti, J. Texter and M. M. Titirici, Polymer, 2010, 51, 4540-4546.

8 L. Zhao, L. Z. Fan, M. Q. Zhou, H. Guan, S. Y. Qiao, M. Antonietti and M. M. Titirici, Adv. Mater., 2010, 22, 5202-5206.

9 Y. Y. Shao, J. H. Sui, G. P. Yin and Y. Z. Gao, Appl. Catal., B, 2008, 79, 89-99.

10 G. Lota, B. Grzyb, H. Machnikowska, J. Machnikowski and E. Frackowiak, Chem. Phys. Lett., 2005, 404, 53-58.

11 P. H. Matter, L. Zhang and U. S. Ozkan, J. Catal., 2006, 239, 83-96.
12 G. Lota, K. Lota and E. Frackowiak, Electrochem. Commun., 2007, 9, 1828-1832.

13 E. Frackowiak, G. Lota, J. Machnikowski, C. Vix-Guterl and F. Beguin, Electrochim. Acta, 2004, 51, 2209-2214.

14 R. Czerw, M. Terrones, J. C. Charlier, X. Blase, B. Foley, R. Kamalakaran, N. Grobert, H. Terrones, D. Tekleab, P. M. Ajayan, W. Blau, M. Ruhle and D. L. Carroll, Nano Lett., 2001, 1, 457-460.

15 A. C. M. Carvalho and M. C. dos Santos, J. Appl. Phys., 2006, 100.

16 E. Frackowiak and F. Beguin, Carbon, 2001, 39, 937-950.

17 E. Frackowiak, Phys. Chem. Chem. Phys., 2007, 9, 1774-1785.

18 R. Jasinski, Nature, 1964, 201, 1212-1213.

19 G. Lalande, R. Cote, D. Guay, J. P. Dodelet, L. T. Weng and P. Bertrand, Electrochim. Acta, 1997, 42, 1379-1388.

20 P. H. Matter and U. S. Ozkan, Catal. Lett., 2006, 109, $115-123$

21 C. W. B. Bezerra, L. Zhang, K. C. Lee, H. S. Liu, A. L. B. Marques, E. P. Marques, H. J. Wang and J. J. Zhang, Electrochim. Acta, 2008, 53, 4937-4951.

22 K. Gong, F. Du, Z. Xia, M. Durstock and L. Dai, Science, 2009, 323, $760-764$.

23 K. A. Kurak and A. B. Anderson, J. Phys. Chem. C, 2009, 113, 6730-6734.

24 T. Q. Lin, F. Q. Huang, J. Liang and Y. X. Wang, Energy Environ. Sci., 2011, 4, 862-865.

25 T. Shirasaki, A. Derre, M. Menetrier, A. Tressaud and S. Flandrois, Carbon, 2000, 38, 1461-1467.

26 P. L. Gai, O. Stephan, K. McGuire, A. M. Rao, M. S. Dresselhaus, G. Dresselhaus and C. Colliex, J. Mater. Chem., 2004, 14, 669-675.

27 R. R. da Silva, J. H. S. Torres and Y. Kopelevich, Phys. Rev. Lett., 2001, 87, 4.

28 E. Z. Kurmaev, A. V. Galakhov, A. Moewes, S. Moehlecke and Y. Kopelevich, Phys. Rev. B: Condens. Matter, 2002, 66, 3.

29 P. A. Denis, Chem. Phys. Lett., 2010, 492, 251-257.

30 A. Chutia, F. Cimpoesu, H. Tsuboi and A. Miyamoto, Chem. Phys. Lett., 2010, 503, 91-96.

31 P. A. Denis, J. Phys. Chem. C, 2009, 113, 5612-5619.

32 J. Y. Dai, J. M. Yuan and P. Giannozzi, Appl. Phys. Lett., 2009, 95, 3 .

33 L. Wang, Y. Z. Zhang, Y. F. Zhang, X. S. Chen and W. Lu, Nanoscale Res. Lett., 2010, 5, 1027-1031.

34 G. Liu, P. Niu, C. H. Sun, S. C. Smith, Z. G. Chen, G. Q. Lu and H. M. Cheng, J. Am. Chem. Soc., 2010, 132, 11642-11648.

35 P. Kuhn, M. Antonietti and A. Thomas, Angew. Chem., Int. Ed., 2008, 47, 3450-3453.

36 P. Kuhn, A. Forget, D. S. Su, A. Thomas and M. Antonietti, J. Am. Chem. Soc., 2008, 130, 13333-13337.

37 J. Schmidt, J. Weber, J. D. Epping, M. Antonietti and A. Thomas, Adv. Mater., 2009, 21, 702-705.

38 N. P. Buu-Hoi, P. Jacquignon, F. Perin and M. Delcey, C. R. Seances Acad. Sci., Ser. C, 1966, 262, 1237-1239.

39 B. L. Moldavskii and Z. I. Kumari, Zh. Obshch. Khim., 1934, 4, 298.

40 C. Hinnen, D. Imbert, J. M. Siffre and P. Marcus, Appl. Surf. Sci., 1994, 78, 219-231.

41 T. J. Moravec and T. W. Orent, J. Vac. Sci. Technol., 1981, 18, 226-228.

42 G. Nanse, E. Papirer, P. Fioux, F. Moguet and A. Tressaud, Carbon, 1997, 35, 175-194.

43 H. K. Jeong, Y. P. Lee, R. Lahaye, M. H. Park, K. H. An, I. J. Kim, C. W. Yang, C. Y. Park, R. S. Ruoff and Y. H. Lee, J. Am. Chem. Soc., 2008, 130, 1362-1366.

44 J. T. Roberts and C. M. Friend, Surf. Sci., 1988, 202, 405-432.

45 B. C. Wiegand, C. M. Friend and J. T. Roberts, Langmuir, 1989, 5 , 1292-1298.

46 B. M. Dekoven and P. L. Hagans, Appl. Surf. Sci., 1986, 27, 199-213.

47 J. J. Schmidt, J. A. Gardella and L. Salvati, Macromolecules, 1989, 22, 4489-4495.

48 B. J. Lindberg, K. Hamrin, G. Johansson, U. Gelius, A. Fahlman, C. Nordling and K. Siegbahn, Phys. Scr., 1970, 1, 286-298. 